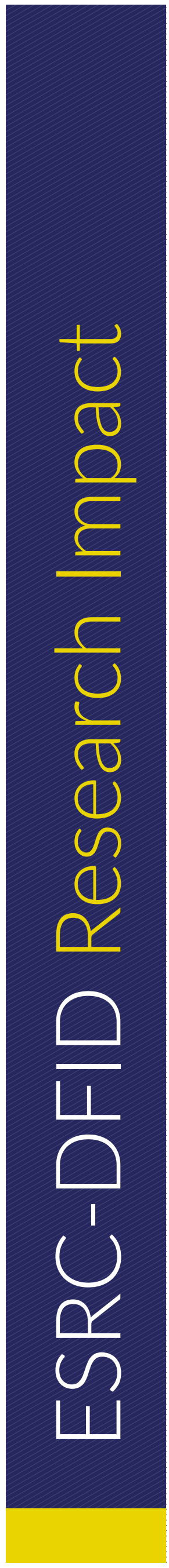

\title{
RAISING AWARENESS OF ENVIRONMENTAL CHANGE IN THE MALDIVES
}

Island communities in the Maldives are experiencing environmental change on a daily basis due to coastal erosion, the accumulation of waste at sea and on beaches, and the rapid expansion of the built environment. Researchers from the Universities of Manchester and Reading in the UK, and the Maldivian NGO ENDEVOR, are working with these communities to understand how such changes affect day-to-day life, and to raise awareness of associated issues amongst decision makers in the national capital, Malé. An exhibition of 40 photographs taken by island inhabitants depicting the challenges they face in their daily lives was held at the National Art Gallery in Malé. The exhibition launch, attended by the photographers and policymakers, proved particularly effective in enabling island residents to raise their concerns and put forward their solutions.

\section{THE CHALLENGE}

The Maldives, an archipelago nation located in the Indian Ocean, is well known internationally for the beauty of its beaches, lagoons, and coral reefs, and also because it is especially vulnerable to the effects of climate change, particularly sea level rise. Less well understood, however, are the political, economic, social, and environmental challenges that the country faces, such as high levels of inequality and a national economy that is heavily reliant on international tourism. Of the 1,200 or so islands that make up the Maldives, around 200 are 'inhabited' with a further 130 'uninhabited' and primarily used as locations for holiday resorts. In recent years, the government has permitted the development of hundreds of guesthouses on the inhabited islands. Being a source of employment and income generation, local people generally support this change; but it has also brought new challenges, in particular a high impact on the environment.

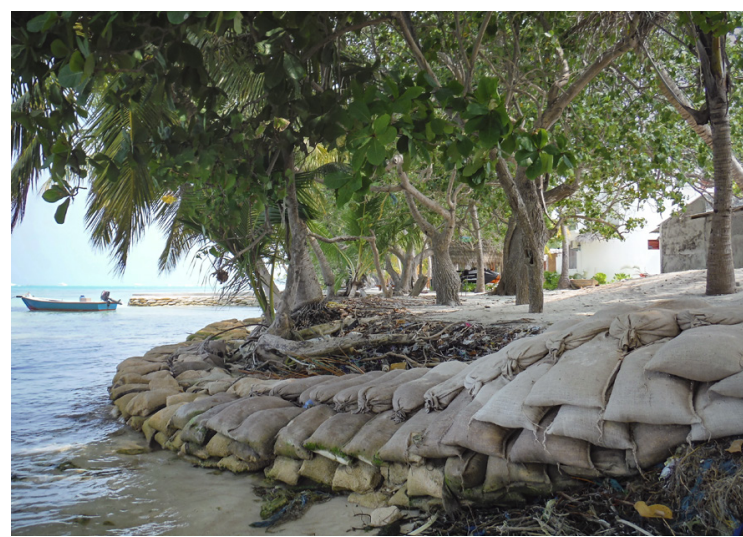

Cover photo: Sandbags piled up to slow down coastal erosion. (c) Alex Arnall.
Environmental change on the islands, whether caused by pollution, coastline engineering, or overuse of groundwater, has a major impact on the quality of people's daily lives. However, because policymakers, politicians, and the media primarily operate from Malé and tend to focus on 'big stories', such as climate change, there is a policy 'gap' between the capital island and the other islands, which can leave island communities feeling frustrated, vulnerable, and disempowered.

\section{THE RESEARCH}

The ESRC-DFID-funded project, 'Everyday Lives and Environmental Change' in the Maldives, conducted research on three small islands located in the North Malé atoll to elicit the lived experiences of island people with regard to their environments. A range of participatory research methods was employed including participant observation, use of the 'go along' technique, interviews, and participatory photography workshops held with community groups. The photography workshops were instrumental in building people's confidence and skills in taking photos to depict their everyday lives and concerns.

The research findings highlighted three important changes occurring on a daily basis on small islands in the Maldives: (1) the erosion of beaches and coastline due to wave action, tidal currents, and human intervention; (2) the daily accumulation of washed-up waste and rubbish deposited by people; and (3) the rapid expansion of the built environment to support guesthouse development and increasing numbers of tourists. There is great concern amongst local populations about the effects that these processes are having on island life. 


\section{THE IMPACT}

The research has raised awareness and contributed to knowledge by better informing policymakers about the effect of environmental change on island communities and raising public awareness in Malé of this issue on the outer islands. The project has also significantly built the capacity of the communities to articulate their concerns and propose locally driven solutions directly to decision makers.

The main project findings were fed back to the island communities where the research was conducted. Findings were also disseminated at a specially and at a seminar at the Maldives National University. A Research Briefing Report has also been distributed to national policymakers, including Malé government and of Tourism, coastal planners, and representatives of the national tourist board.

Forty of the photographs taken by island residents during the community photography workshops were displayed at the National Art Gallery. The exhibition launch brought together policymakers, including representatives of international organisations such as UNDP, national government departments, and NGOs, and students and island residents to discuss the impacts and management of environmental change taking place on the islands. During the event, the photographers explained the changes that they and their communities are facing. A member of an island council reported that this was a highly effective method to demonstrate challenges and to propose possible solutions. One island council had its planning permission application for the erection of coastal defences to prevent rapid beach erosion approved the day immediately following the launch, and it was felt by the council that the exhibition had directly contributed to this positive outcome.

The four-day photography exhibition raised public awareness in Malé. Two project investigators, Uma Kothari and Mizna Mohamed, were subsequently invited onto the national daytime television programme Hedhunu Hedhunaa to discuss the purpose of the exhibition and highlight environmental impacts on outer islands. An island resident appreciated 'the opportunity to participate in the photography exhibition. It has helped us make people in Malé understand the challenges that we face with the development of our island'. The photography workshops were key to building the confidence of community groups by on self-expression through visual imagery as a means to put forward a policy message. organised Research Impact workshop at Cyryx College officials in the Ministries of Environment and Energy placing value on people's perspectives and focusing

The research team now plans to take the photography exhibition to schools in Malé and on to some of the outer islands. The aim is to further raise awareness of environmental changes taking place in other locations and to build understanding of the power of photography to communicate the changes that are occurring in people's day-to-day lives. There are also plans for further policy engagement. Following a change of government, the new administration is looking to develop a series of fresh initiatives focusing on local environmental change, particularly the problems associated with plastic waste. The project team is seeking an appointment with the newly appointed president of the Maldives.

\section{FURTHER READING}

Arnall, A. and Kothari, U. (2015) 'Challenging Climate Change and Migration Discourse: Different Understandings of Time-Scale and Temporality in the Maldives', Global Environmental Change 31: 199-206

Kothari, U. and Arnall, A. (2019) 'Everyday Life and Environmental Change', Geographical Journal 185.2: 130-141

Kothari, U.; Arnall, A. and Mohamed, M. (2019) Everyday Lives and Environmental Change: Research Briefing Report, Manchester: University of Manchester, http://hummedia.manchester.ac.uk/institutes/gdi/ research/FINAL\%20Briefing\%2Oreport\%2031\%20 May\%202019.pdf (accessed 5 August 2019)

Kusenbach, M. (2016) 'The Go-Along Method', in Anja Schwanhäußer (Ed.) Sensing the City. A Companion to Urban Anthropology, Basel: Birkhäuser: 154-158, https://ignazstrebel.files.wordpress.com/2017/09/goalong_kuschenbach_16.pdf (accessed 10 July 2019)

Rasheed, A. (2018) Reflections on Community, Education and Nature in the Maldives, Everyday Lives ins the Maldives blog, 21 January, https://sites. manchester.ac.uk/everyday-lives/2019/01/21/ reflections-on-community-education-and-nature-inthe-maldives/ (accessed 23 July 2019)

UNDP (2018) Island Life 3, January-December, United Nations Development Programme, www.undp.org/ content/dam/maldives/docs/publicationsgeneral/ IslandLifeMag_Webversion.pdf (accessed 23 July 2019)

\section{THE IMPACT INITIATIVE}

\section{For International Development Research}

The Impact Initiative seeks to connect policymakers and practitioners with the world-class social science research supported by the ESRC-DFID Strategic Partnership, maximising the uptake and impact of research from: (i) the Joint Fund for Poverty Alleviation Research, and (ii) the Raising Learning Outcomes in Education Systems Programme. We seek to identify synergies between these programmes and their grant holders, support them to exploit influencing and engagement opportunities, and facilitate mutual learning. The Impact Initiative is a collaboration between the Institute of Development Studies (IDS) and the University of Cambridge's Research for Equitable Access and Learning (REAL) Centre.

All content is available under the Open Government License v3.0, except where otherwise stated.

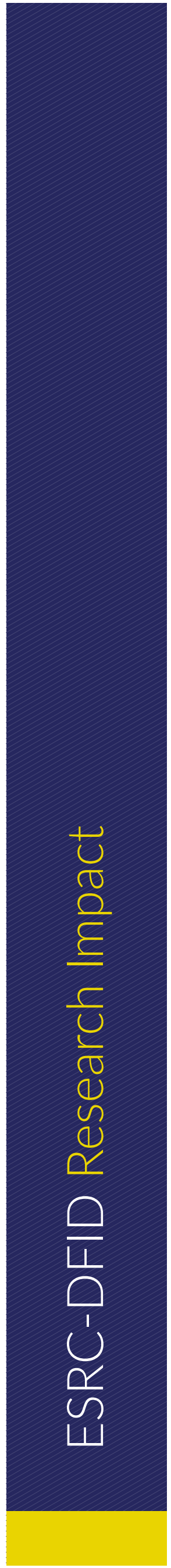

